\title{
A Hospital-based Observational Study on the Characterization and Correlation of Magnetic Resonance Imaging Patterns with Clinical Findings on Cerebral Palsy
}

\author{
Muthiah Muthu Magesh ${ }^{1}$, V.V. Hattiholi ${ }^{1}$, Mahesh Kamate ${ }^{1}$ \\ ${ }^{1}$ Department of Radio Diagnosis, KLE's Jawaharlal Nehru Medical College, Belgaum, Karnataka 590010, India
}

Corresponding author: V. V. Hattiholi, Department of Radio Diagnosis, KLE's Jawaharlal Nehru Medical College, Belgaum, Karnataka 590010, India

DOI: http://dx.doi.org/10.21276/ijcmsr.2018.3.4.26

How to cite this article: Muthiah Muthu Magesh, V.V. Hattiholi, Mahesh Kamate. A hospital-based observational study on the characterization and correlation of magnetic resonance imaging patterns with clinical findings on cerebral palsy. International Journal of Contemporary Medicine Surgery and Radiology. 2018;3(4):D112-D117.

\section{A B S T R A C T}

Introduction: Evidence suggests that the diagnosis of cerebral palsy complemented by magnetic resonance imaging (MRI) has potential to differentiate changes in the various types of cerebral palsy, especially the pathologic conditions. This study explored the MRI patterns in children with cerebral palsy and their association with clinical findings.

Material and methods: The observational study included a total of 200 children clinically diagnosed with cerebral palsy using MRI brain scan from January 2014 to December 2014. The process of imaging was preceded by demographic data collection (age and sex) along with birth and maternal history. Data collected were coded in Microsoft Excel Worksheet. However, the continuous data were expressed in terms of mean \pm standard deviation (SD).

Results: The clinical characteristics revealed quadriplegia and diplegia in $26.5 \%$ and $25 \%$ of the children, respectively. Spastic cerebral palsy was noted in majority of the children (64\%) with most of the children diagnosed with spastic diplegia (24.5\%) followed by spastic quadriplegia (23\%). MRI brain scan revealed $29.50 \%$ of the children with posterior involvement and most common MRI finding was periventricular white matter (47\%). Some of the other findings were porencephalic cysts (14\%) and myelination (11.5\%). Periventricular leukomalacia (38\%) was the common diagnosis on MRI scanning followed by cystic degeneration, and basal ganglia involvement (11.5\% each). The MRI diagnosis correlated well with clinical diagnosis (80.5\%).

Conclusion: MRI is a useful diagnostic tool, which helps to detect pathologic abnormalities in patients with cerebral palsy and correlates well with clinical diagnosis.

Key words: Cerebral Palsy; Magnetic Resonance Imaging; Periventricular Leukomalacia

\section{INTRODUCTION}

Cerebral palsy $(\mathrm{CP})$ is a set of neurological disorders, which permanently affects the movements of the body along with muscle coordination in infants or young children aged up to 3 years. ${ }^{1,2}$ However, the lesions present only in the region of the brain are said to be characteristic of $\mathrm{CP} .^{1}$

The worldwide incidence of $\mathrm{CP}$ is approximately 1.5 to 4 per 1000 live births, as reported by CDC in $2016 .{ }^{3}$ On the other hand, approximately $15-20 \%$ of the physically handicapped children in India are said to be suffering from CP. According to a recent survey, approximately 25 lakh of children in India are reported to be diagnosed with this condition. ${ }^{4}$ However, the prevalence of $\mathrm{CP}$ is strongly linked with the gestational age, possibly due to malformation or damage of the brain during the developmental stage. Although prematurity is among the various risk factors of $\mathrm{CP}$, maximum number of reported cases are of full-term infants due to increased number of full-term infants born as compared to the preterm babies. $^{5}$
Historically, birth trauma has often been associated with $\mathrm{CP}$, but the recent studies have implicated genetic, traumatic, metabolic, inflammatory, anoxic, and congenital conditions as the leading causes of $\mathrm{CP}$. The commonly known risk factors (prenatal) include conditions of chorioamnionitis, placental complications, intrauterine infections, and longterm exposure to teratogens. Maternal conditions such as a history of seizures, hyperthyroidism, and mental retardation also contribute to its development to some extent. As a result, each case of $\mathrm{CP}$ is distinct in nature. Moreover, the ongoing prospective studies are focusing on inflammatory-mediated models of CP along with the its sequence of development, as past studies have termed prenatal events such as low weight, infection, hyperbilirubinemia, intracranial hemorrhage, seizure, and hypoglycemia as possibilities for neurological sequelae of $\mathrm{CP}{ }^{6}$

Since parents and pediatricians are among the first few people to notice the development of abnormal motor movements, their concerns aid in the early diagnosis of CP. However, risk factors may be revealed by analyzing the 
history of the child. ${ }^{7}$ Assessment of CP can be done at the earliest by observing the persistence of primitive reflexes and impairments in strength, tone, and control of muscles along with variation in involuntary movements and delayed progress of postural responses. The functional limitations can also be analyzed for detecting CP using motor quotient. ${ }^{8-10}$ However, methods of detection have become advanced with the development of unconventional techniques such as computed tomography (CT) and magnetic resonance imaging (MRI). These techniques are preferred, as they help in correlating radiographic and clinical data with respect to pre-, peri-, and postnatal asphyxia by detecting morphological changes in the cerebral white matter. ${ }^{11} \mathrm{On}$ comparison of CT with MRI, it is found that the sensitivity of MRI in detection of malformations such as callosal hypogenesis and polymicrogyria in brain is far superior than CT. Hence, MRI is usually preferred over CT for diagnosing $\mathrm{CP}$ or its cause. ${ }^{7,12,13}$

Several clinical and neurological studies have been conducted to evaluate the events before and after birth leading to the development of CP. ${ }^{14-19}$ However, the studies pertaining to clinical data in the case of prenatal care and insults are limited and information are available only on histological analysis. On the other hand, neuroradiologic studies have been restricted in their usefulness before the introduction of imaging by means of CT and MRI. Hence, the present study was undertaken to characterize the MRI patterns in children with $\mathrm{CP}$ and find their association with the clinical findings.

\section{MATERIAL AND METHODS}

The present observational study was conducted at the Department of Radio diagnosis, KLES Dr. Prabhakar Kore Hospital and Medical Research Centre, Belgaum for a period of 1 year from January 2014 to December 2014. The study included a total of 200 children aged 10 years or less who were undergoing neuroimaging and have previously been diagnosed with $\mathrm{CP}$ on the basis of clinical findings. However, children with the presence of metabolic disorders or neuroimaging suggestive of metabolic disorders, history of developmental regression or inflammatory brain diseases such as meningitis, encephalitis, and intracranial spaceoccupying lesions (presence of brain abscess, tuberculoma, neurocysticercosis, and neoplastic lesions of cerebral cortex) are excluded from the study.

Data on the demographic characteristics (age and sex) along with birth and maternal history were collected based on interview. Information regarding the clinical type and nature of $\mathrm{CP}$ were noted on a predesigned and pretested proforma from the medical records of Child Development Clinic.

Imaging of the brain was done for analyzing the type and nature of CP with the help of SYNGO 2002 B 1.5-T MRI manufactured by SIEMENS. The scans performed included parameters such as field of view $(14-24 \mathrm{~cm})$, slice thickness $(10,5$, and $3 \mathrm{~mm})$, matrix size $(256 \times 256)$ and sequences (T1, T2, fluid-attenuated inversion recovery (FLAIR), and diffusion-weighted axial images, coronal T2 and sagittal T1 sequences) (Figs. 1 and 2). ${ }^{20}$ The study of correlation between MRI diagnosis and clinical diagnosis was done after obtaining conclusions from clinical diagnosis. Non-cooperative subjects were administered with a sedative (pedicloryl syrup) under the supervision of a trained anesthesiologist.

The study was approved and provided with Ethical clearance from the Institutional Ethics Committee of Jawaharlal Nehru Medical College, Belgaum before the commencement. Additionally, parental consent of the selected children was obtained in written before their enrolment in the study.

\section{STATISTICAL ANALYSIS}

The data obtained (expressed as rates, ratios, proportions, and percentages) were coded and entered into Microsoft Excel Worksheet. However, the continuous data were expressed in terms of mean \pm standard deviation (SD). The data obtained for correlation study were determined by percentage agreement.

\section{RESULTS}

The demographic data revealed male to female ration to be $1.40: 1$ where $58.5 \%$ of the children were boys and $41.5 \%$ were girls. Most of the children diagnosed with $\mathrm{CP}$ were in

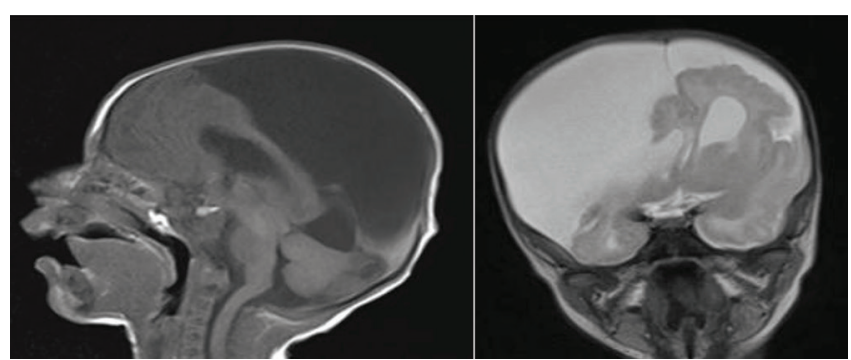

Figure-1: T1 Sagittal and T2 coronal images of a 6-monthold boy with history of birth asphyxia and spastic hemiplegia
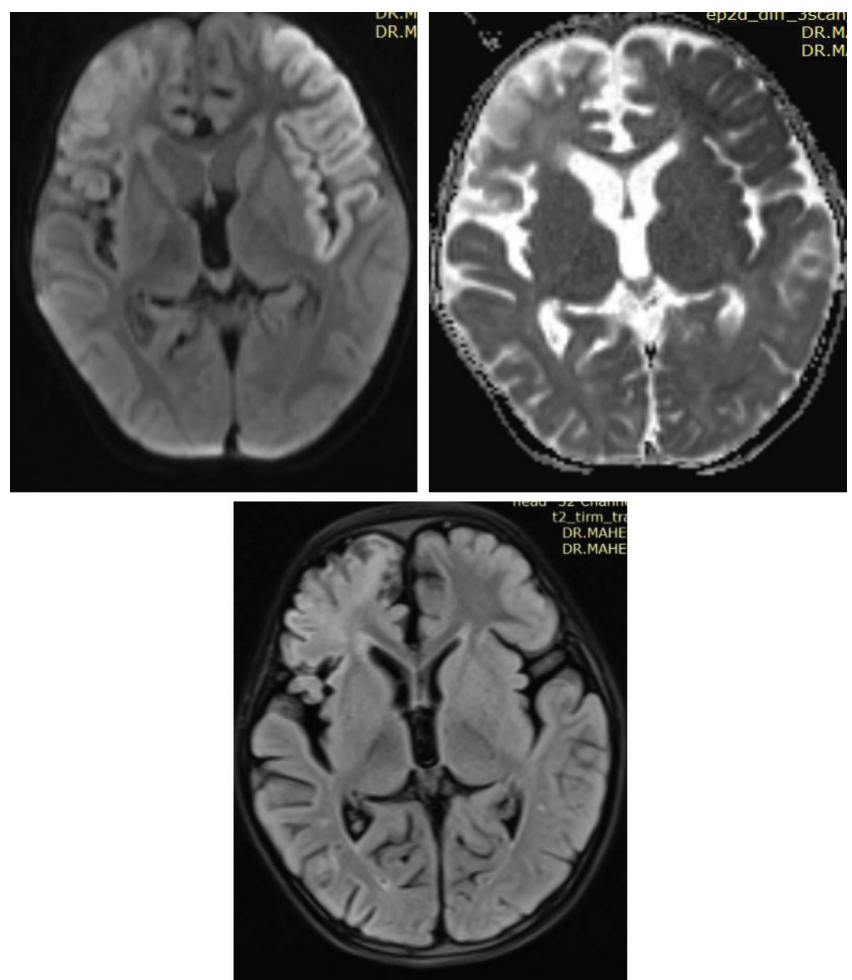

Figure-2: Diffusion-weighted imaging and fluid-attenuated inversion recovery images showing in a 3-year-old girl with spastic hemiplegia 


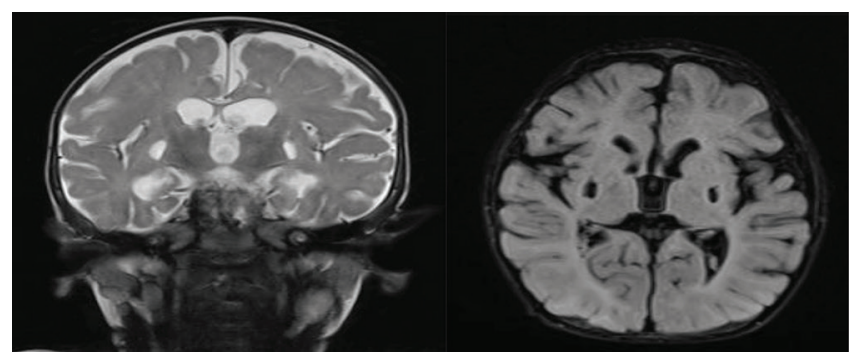

Figure-3: A 7-month-old boy with dystonic cerebral palsy showing coronal T2 and fluid-attenuated inversion recovery axial images with focal gliosis

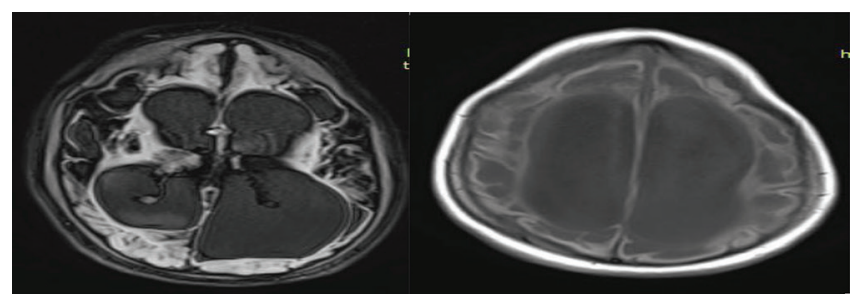

Figure-4: FLAIR and T1 axial images of a 3-year-old girl with spastic quadriplegia

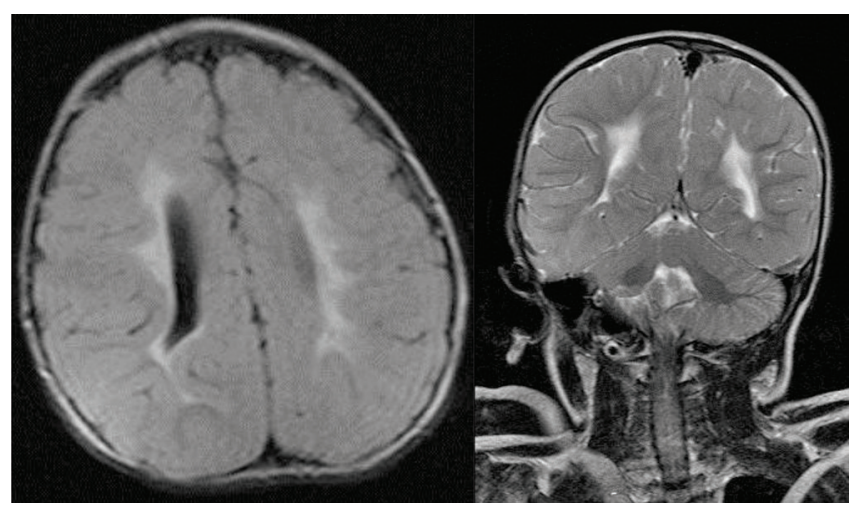

Figure-5: T1 axial and T2 coronal showing areas of T1 hyperintensity within larger areas of $\mathrm{T} 2$ hyperintensity in a 2-year-old girl with spastic diplegic cerebral palsy

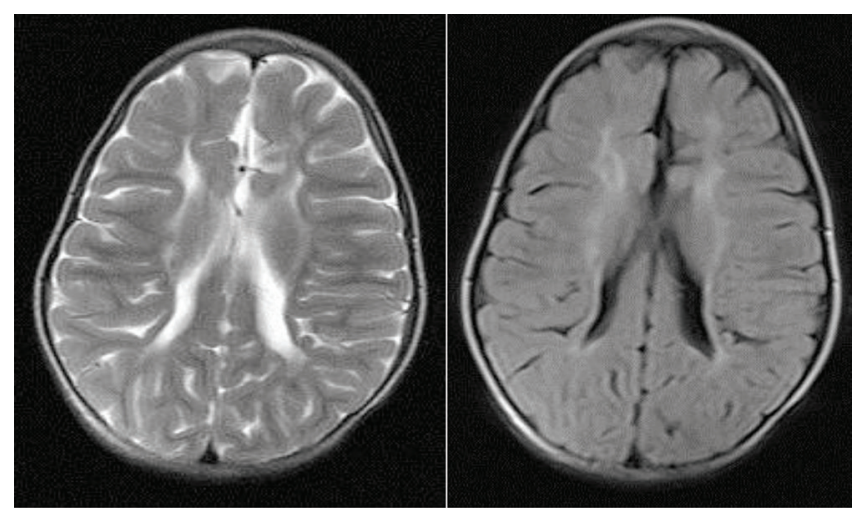

Figure-6: A 4-year-old boy with moderate periventricular leukomalacia and spastic diplegia

age-group of 1-6 years (59.5\%) followed by 7-10 years agegroup (21\%). The rest of the children were below 1 year of age. The mean age of the children with $\mathrm{CP}$ was $3.94 \pm 3.06$ years.

Analysis of maternal history revealed that $37 \%$ of the subjects were preterm and $63 \%$ were full term babies. It was also found that, among the 200 children evaluated, $24.50 \%$ had the history of consanguineous marriage among parents. Lack of antenatal care and home-based delivery was reported by $4.5 \%$ and $3 \%$ of the mothers, respectively. The mode of delivery was lower segment caesarean section in $20.5 \%$ while instrumental in $10.5 \%$ of the babies. Also, complications of urinary tract infection, gestational diabetes mellitus, multiple gestation, premature rupture of membranes and per vaginal bleeding were reported by $14.5 \%, 7 \%, 5 \%, 1 \%$, and $0.5 \%$ of the mothers, respectively.

History taking revealed that $43.5 \%$ of the children had low birth weight $(<2.49 \mathrm{~kg})$ whereas $56.5 \%$ of children were found to have more than $2.50 \mathrm{~kg}$ of birth weight. It was also reported that $56.50 \%$ of the children were first-born whereas $29.5 \%, 11.5 \%$ and $2.5 \%$ of children were second, third, and fourth born, respectively. Study revealed that most of the children (58.5\%) cried immediately after birth while delay and weak cry were noted in $32.5 \%$ and $9 \%$ of the babies, respectively. The process of resuscitation was done in $27 \%$ of the children and a history of neonatal intensive care unit (NICU) admission was noted in $62 \%$ of the children. Jaundice (19.5\%), feeding problems (16.5\%), and seizures (12\%) were the predominant causes followed by cases of respiratory distress syndrome $(6.5 \%)$, septicaemia (3\%), and cyanosis $(0.50 \%)$.

Most of the children had been diagnosed to have quadriplegia (26.5\%) followed by diplegia (25\%), dyskinesia (19.5\%), hemiplegia $(13.5 \%)$, and triplegia $(0.5 \%)$. With regard to nature of $\mathrm{CP}$, spastic $\mathrm{CP}$ was noted in nearly two-third of the total number of children (64\%), and conditions of dystonic (13\%), choreoathetoid (10\%), and ataxia (5.5\%) were present in the remaining children (Figs. 3-4). Based on these evaluations (maternal history, birth history, type and nature of $\mathrm{CP}$ ) the most common clinical diagnosis was spastic diplegia (24.5\%) and spastic quadriplegia (23\%) (Fig. 5). The other diagnoses noted were spastic hemiplegia (12\%), dystonic (14\%), choreoathetoid (10.5\%), dyskinetic $(8.5 \%)$, mixed (3\%), ataxic (3\%), hypotonic (1\%), and spastic triplegia (0.50\%). Malformations were found in $8.2 \%$ of the children. Among those with white matter injury, 52\% were born preterm and spastic bilateral $\mathrm{CP}$ was the most common subtype (47\%). However, $80 \%$ of the children with focal cortical lesions were reported to have unilateral CP.

In the present study, $29.5 \%$ of the children upon imaging with MRI demonstrated posterior involvement and $16.5 \%$ of the children displayed anterior and middle area involvement of the brain. However, $14.50 \%$ of the children were found to have involvement of the middle and posterior region, whereas $8 \%, 5 \%$, and $4.5 \%$ of the children had the involvement of middle, anterior middle, and posterior and anterior regions of the brain, respectively. Of the total 200 children, approximately $22 \%$ were normal. The most common MRI finding was periventricular white matter (47\%) followed by cerebral cortex $(34.5 \%)$, corpus callosum $(22.5 \%)$, thalamus (14\%), globus pallidus (10.5\%), cerebral cortex (8.5\%), putamen $(8 \%)$, caudate nucleus $(6.5 \%)$, internal capsule (5.5\%), and cerebellar white matter $(0.5 \%)$. The other common findings noted were porencephalic cysts (14\%), myelination (11.5\%), ventricular enlargement and cerebellar 


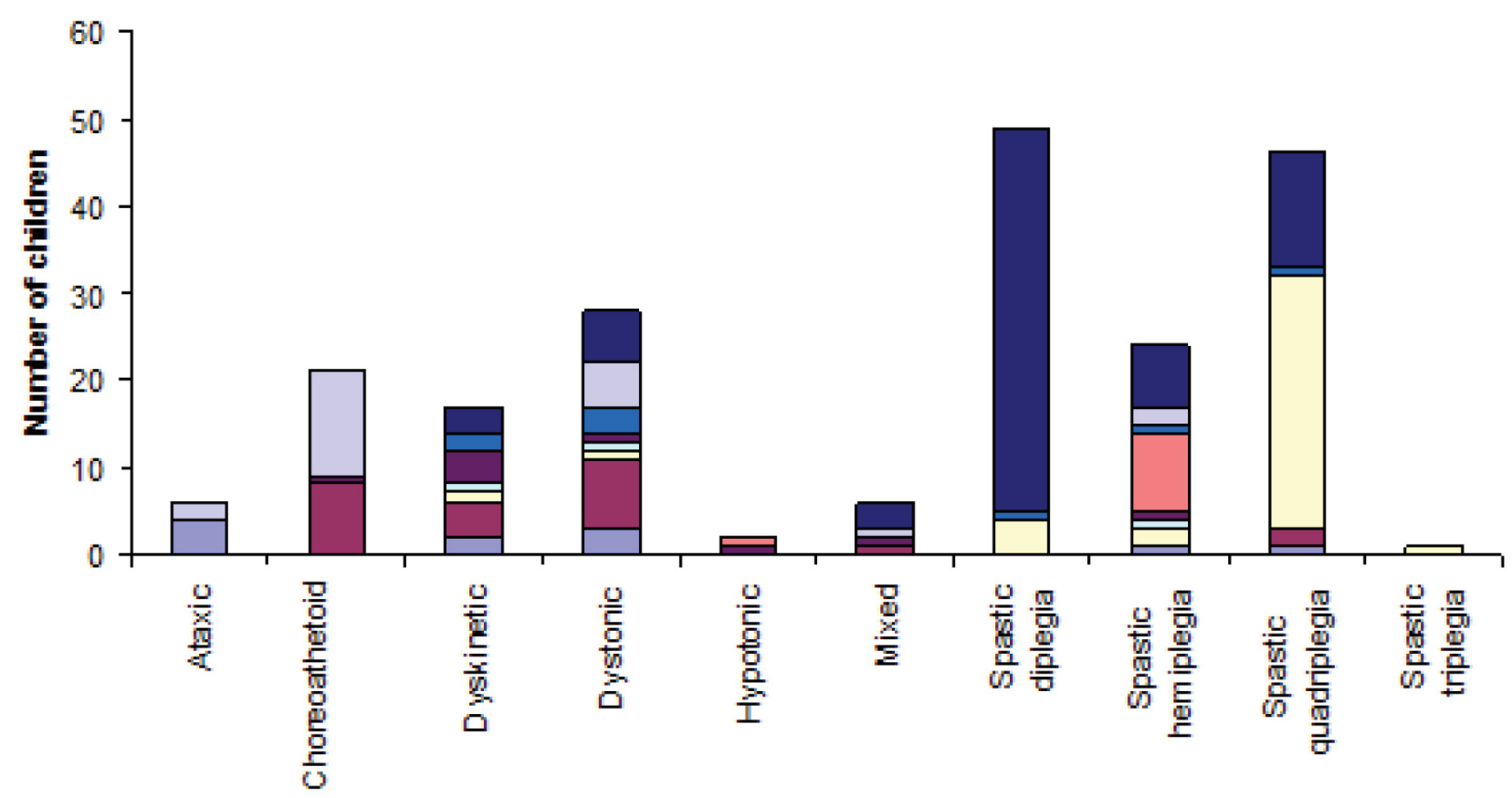

Clinical diagnosis

\begin{tabular}{|lll|}
\hline$\square$ Atrophy & Basal ganglia & $\square$ Cystic degeneration \\
$\square$ Demyelination & $\square$ Focal gliosis & $\square$ Infirct \\
$\square$ Malform ation & $\square$ Normal & $\square$ Periventricular leukomalacia \\
\hline
\end{tabular}

Figure-7: Correlation between MRI and Clinical diagnosis of cerebral palsy

atrophy (11\% each), focal infarct (5\%), malformation (4\%) and enlargement of pericerebral subarachnoid spaces. Based on these findings, the most common MRI diagnosis was periventricular leukomalacia (38\%) (Fig. 6) followed by cystic degeneration (19\%), basal ganglia involvement (11.5\%), atrophy (5.5\%), infarct (5\%), focal gliosis (4.5\%), malformation (4\%), and demyelination (1.5\%). Rest of the subjects (11\%) were normal. Among the children with periventricular leukomalacia, the predominant area was posterior white matter $(42.11 \%)$ followed by anterior and middle (23.68\%), middle and posterior (23.68\%), middle (7.89\%), anterior (1.32\%), and anterior, middle and posterior (1.32\%).

In this study, MRI findings correlated well with clinical diagnosis of patients with spastic triplegia (100\%), spastic diplegia (100\%), choreoathetoid (95.24\%), and spastic quadriplegia (91.3\%). The least correlation was noted with dyskinetic (47.06\%), mixed (50\%), and hypotonic (50\%) (Fig. 7).

\section{DISCUSSION}

Due to incidence of $\mathrm{CP}$ at infancy/young age, it has become an important social and medical problem..$^{21-23}$ The multiplicity of symptoms in $\mathrm{CP}$ is due to the injuries in different parts of the brain-motor cortex (limb paresis), basal ganglia (involuntary movements), and cerebellum (congruity disorder of movement and balance). ${ }^{24}$ However, its prevalence has decreased in the recent years as a result of improvement in maternal care and pediatrics.

Recently, apart from the contemporary diagnostic tools, advanced techniques of neuroimaging- $\mathrm{CT}$ and MRI have been used to diagnose malformations or insults to the brain such as the condition of CP. Several studies have supported the fact that MRI has the potential to differentiate various forms of $\mathrm{CP}$ with respect to detecting different changes observed in each form. ${ }^{24,25}$ Moreover, MRI has been reported to have high correlation with the findings of clinical examination ${ }^{26}$ suggesting the need of a MRI scan for every suspected patient to determine the form/stage of $\mathrm{CP}$ along with predicting their future needs.

The present hospital-based observational study was therefore undertaken to correlate the characterized MRI scans with the clinical findings in CP. Slight male preponderance was noted in the present study which was in accordance with studies conducted by Najar et al. ${ }^{27}$ and Hoon et al. ${ }^{28}$ Similarly, in an European CP study, ${ }^{26} 61.9 \%$ of the children were boys. However, Yamada et al., ${ }^{29}$ out of 38 children, observed female preponderance with $60.52 \%$ of the children being girls.

With respect to the age, the present study reported maximum incidence of $\mathrm{CP}$ in children aged 1-10 years. The mean age was observed to be $3.94 \pm 3.06$ years. In a similar study by Bax et al. ${ }^{26}$, the age at the time of examination ranged from 12 to 91 months, with a mean age of 46 months. However, a recent study by Dobhal et al. ${ }^{30}$ reported the mean age for children diagnosed with $\mathrm{CP}$ as 61 months. In another study by Najar et al. ${ }^{27}$, the $2-5$ years age-group accounted for $78.94 \%$ of total children with $\mathrm{CP}$ and the least involved age-group was 11-16 years (3.50\%). The differences observed in the pattern of age distribution in all the present studies, including the present study, can be explained by the inclusion of different 
age-groups with varying sample size of the study population. The present study indicated that about $24.50 \%$ of the children diagnosed with $\mathrm{CP}$ had the history of consanguineous marriage among parents. A study on consanguineous marriage also reported the prevalence of $\mathrm{CP}$ in related parents. ${ }^{31}$ The well-being of the mother is also an essential factor in the development of CP. Complications such as urinary tract infections and gestational diabetes indicates poor health of the mother which has been observed in the present study. ${ }^{32}$

The order of birth has also been considered as a factor for the development of CP. In the present study, majority of the children were first-born. Similar observations were reported by Russell ${ }^{33}$ in which $63 \%$ of the 38 twins considered for the study were first born.

The diagnosis and nature of the $\mathrm{CP}$ was also determined in the children as part of the present study where majority of the children were diagnosed with quadriplegia and the nature of $\mathrm{CP}$ was reported to be spastic CP. In a similar study by Najar et al., ${ }^{27}$ most common type of CP observed was spastic diplegia contributing to $49.10 \%$ of all cases. However, Bax et al. ${ }^{26}$ reported that maximum number of children was diagnosed with diplegia (34.4\%) followed by hemiplegia (26.2\%), spastic quadriplegia (18.6\%), and dyskinesia (14.4\%). Recently Anderson et al. ${ }^{34}$ described the distribution of different MRI patterns in children with different subtypes of CP. Among 711 (60.4\%) children with CP and available brain MRI, $14.2 \%$ had normal findings with spastic bilateral subtype being the most common (48.5\%); while white matter injury was the most common lesion (48\%), followed by focal cortical (18.6\%), diffuse cortical (14.1\%), and basal ganglia lesions (13.2\%).

Further analysis of the CP in children included MRI scans to analyse the area involved in the brain and the detection of cysts, myelination, ventricular enlargement and other malformations. The scans revealed maximum involvement of the posterior region and the presence of periventricular white matter and cerebral cortex. Based on the observations, periventricular leukomalacia was stated as the most common diagnosis where the predominant area was posterior white matter. These observations were consistent with several other studies.

Bax et al. ${ }^{26}$ reported that white matter damage of immaturity was the most common finding (42.5\%) followed by basal ganglia lesions (12.8\%), cortical/subcortical lesions (9.4\%), malformations (9.1\%), focal infarcts (7.4\%), and miscellaneous lesions (7.1\%). Similarly, population-based studies of brain imaging patterns in $\mathrm{CP}^{35}$ also reported white matter injury as the most common imaging pattern for all children with CP, occurring in $19-45 \%$ of cases across three studies. Krageloh-Mann and Horber ${ }^{36}$ reported white matter injury in 56\% of scans, but the results were not directly comparable since their review only included spasticdyskinetic CP. A systematic review of studies $^{36}$ using MRI in children with $\mathrm{CP}$ reported that out of 388 children,334 (86\%) had abnormal MRI. and Periventricular white matter lesions were most frequent (56\%) followed by cortical and deep grey matter lesions (18\%). Brain malformations were rather rare, described in only $9 \%$ of the cases. In a study by Najar et al., ${ }^{27}$ the most common MRI abnormality was periventricular lesion (38.59\%); however, Kwong et al. ${ }^{37}$ and Gururaj et al. ${ }^{38}$ reported higher rate of periventricular lesions in $66 \%$ and $57 \%$ of total cases, respectively. A review ${ }^{35}$ based on evidence from three population-based cohorts suggested that MRI, or a combination of MRI, and CT, identify abnormality in $86 \%$ of children with $\mathrm{CP} .{ }^{39-41}$ However, in the present study MRI findings were normal in $11 \%$ of the children. Similar proportion of normal MRI findings was reported in the European CP study (11.7\%). ${ }^{26}$

Conclusion

The overall correlation of MRI findings with clinical diagnosis was $80.5 \%$. These findings suggest that, as MRI has high correlation with clinical diagnosis, it can be a valuable tool in determining the pathological abnormalities and etiology of the patients with $\mathrm{CP}$ and thus, can help in making better prognosis of CP. However, further studies may focus on etiological aspects of $\mathrm{CP}$ and create awareness of possible preventive measures which will help in reducing the huge burden of the $\mathrm{CP}$.

\section{REFERENCES}

1. Microbial Evolution and Co-Adaptation: A Tribute to the Life and Scientific Legacies of Joshua Lederberg: Workshop Summary. The National Academies Collection: Reports funded by National Institutes of Health. Washington (DC) 2009.

2. Koman LA, Smith BP, Shilt JS. Cerebral palsy. Lancet. 2004;363(1):1619-31.

3. Prevention CfDca. Data \& Statistics for Cerebral Palsy [cited 201616 August].

4. Vyas AG, Kori VK, Rajagopala S, Patel KS. Etiopathological study on cerebral palsy and its management by Shashtika Shali Pinda Sweda and Samvardhana Ghrita. Ayu. 2013;34(3):56-62.

5. Jan MMS. Manual of child neurology: problem based approach to common disorders: Bentham science Publishers; $2012.7 \mathrm{p}$.

6. Linda S. Nield SN, Jean Someshwar, Florence C. Dalcanto, Shiv Someshwar, John J. Collins and Margaret Jaynes. Cerebral Palsy: A Multisystem Review. Consultant for pediatricians. 2007;6.

7. Ashwal S, Russman BS, Blasco PA, Miller G, Sandler A, Shevell M, et al. Practice parameter: diagnostic assessment of the child with cerebral palsy: report of the Quality Standards Subcommittee of the American Academy of Neurology and the Practice Committee of the Child Neurology Society. Neurology. 2004;62 (5):851-63.

8. Palmer FB. Strategies for the early diagnosis of cerebral palsy. The Journal of pediatrics. 2004;145 (2):S8-S11.

9. Hadders-Algra M. Early diagnosis and early intervention in cerebral palsy. Frontiers in neurology. 2014;5 (2):185.

10. Arvind Vasudevan AK. Photoclinic: Lesch-Nyhan Syndrome. Consultant for pediatricians. 2006;5 (1):322.

11. Truwit CL, Barkovich AJ, Koch TK, Ferriero DM. Cerebral palsy: MR findings in 40 patients. AJNR American journal of neuroradiology. 1992;13 (3):67-78.

12. Jaw TS, Jong YJ, Sheu RS, Liu GC, Chou MS, Yang 
RC. Etiology, timing of insult, and neuropathology of cerebral palsy evaluated with magnetic resonance imaging. Journal of the Formosan Medical Association = Taiwan yi zhi. 1998;97 (5):239-46.

13. Accardo J, Kammann H, Hoon AH, Jr. Neuroimaging in cerebral palsy. The Journal of pediatrics. 2004;145 (6):S19-27.

14. Adsett DB, Fitz CR, Hill A. Hypoxic-ischaemic cerebral injury in the term newborn: correlation of CT findings with neurological outcome. Developmental medicine and child neurology. 1985;27 (1):155-60.

15. Blair E, Stanley FJ. Intrapartum asphyxia: a rare cause of cerebral palsy. The Journal of pediatrics. 1988;112 (6):515-9.

16. Eastman NJaD, M. The Etiology of Cerebral Palsy. American Journal of Obstetrics and Gynecology. 1955;69 (3):11.

17. Nelson KB, Ellenberg JH. Antecedents of cerebral palsy. Multivariate analysis of risk. The New England journal of medicine. 1986;315 (1):81-6.

18. Wiklund LM UP, Flodmark O. Morphology of cerebral lesions in children with congenital hemiplegia. Neuroradiology. 1990;32 (2):7.

19. Kolawole TM, Patel PJ, Mahdi AH. Computed tomographic (CT) scans in cerebral palsy (CP). Pediatric radiology. 1989;20 (1):23-7.

20. Chavhan GB, Babyn PS, Thomas B, Shroff MM, Haacke EM. Principles, techniques, and applications of T2*-based MR imaging and its special applications. Radiographics: a review publication of the Radiological Society of North America, Inc. 2009;29 (4):1433-49.

21. Petrini JR, Dias T, McCormick MC, Massolo ML, Green NS, Escobar GJ. Increased risk of adverse neurological development for late preterm infants. The Journal of pediatrics. 2009;154 (1):169-76.

22. E. KPMEG. Selected risk factors for spastic cerebral palsy in a retrospective hospital-based case control study. Prog Health Sci. 2014;4 (3):6.

23. D Otapowicz WS, B Okurowska-Zawada, B Artemowicz, K Sendrowski, W Kułak, L Boćkowski, J Kuzia-Śmigielska. Dysphagia in children with infantile cerebral palsy. Adv Med Sci 2010;55.

24. Gościk E KW, Gościk J, Gościk J, Okurowska-Zawada $\mathrm{B}$, Tarasow E. The cerebellum in children with spastic cerebral palsy: Volumetrics MRI study. Prog Health Sci 2011;1 (5):8.

25. (U.S.) NIoNDaS. Cerebral Palsy: Hope Through Research: NIH Publication 2013 [cited 201616 August]. Available from: http://www.ninds.nih.gov/ disorders/cerebral_palsy/detail_cerebral_palsy.html.

26. Martin Bax CT, Olof Flodmark. Clinical and MRI Correlates of Cerebral Palsy: The European Cerebral Palsy Study. JAMA. 2006;296 (1):6.

27. Najar BA, Kachroo A, Gattoo IA, Hussain SQ. Cerebral palsy: risk factors, comorbidities and associated MRI findings, a hospital based observational study. Int J Contemp Pediatr. 2015;2 (6):90-5.

28. Hoon AH, Jr., Vasconcellos Faria A. Pathogenesis, neuroimaging and management in children with cerebral palsy born preterm. Developmental disabilities research reviews. 2010;16 (4):302-12.
29. Yamada K, Itoh M, Fueki N, Hirasawa K, Suzuki N, Kurata $\mathrm{K}$, et al. [The cranial MRI in severe cerebral palsy: a comparative study with clinical data]. No to hattatsu Brain and development. 1993;25 (1):435-41.

30. Dobhal M, Juneja M, Jain R, Sairam S, Thiagarajan D. Health-related quality of life in children with cerebral palsy and their families. Indian pediatrics. 2014;51 (3):385-7.

31. Mohammadi MM,Hooman HA,AfroozGA, Daramadi PS. The relationship between consanguineous marriage and death in fetus and infants. Journal of research in medical sciences: the official journal of Isfahan University of Medical Sciences. 2012;17 (2):448-51.

32. Wu CS, Pedersen LH, Miller JE, Sun Y, Streja E, Uldall $\mathrm{P}$, et al. Risk of cerebral palsy and childhood epilepsy related to infections before or during pregnancy. PloS one. 2013;8 (1):e57552.

33. Russell EM. Cerebral palsied twins. Archives of disease in childhood. 1961;36:328-36.

34. GL Andersen JS, SJ Hollung, T Vik. PS-248 Cerebral Mri Findings In Children With Cerebral Palsy (cp) In Norway. Archives of disease in childhood. 2014;99 (6):A202.

35. Reid SM, Dagia CD, Ditchfield MR, Carlin JB, Reddihough DS. Population-based studies of brain imaging patterns in cerebral palsy. Developmental medicine and child neurology. 2014;56 (5):222-32.

36. Krageloh-Mann I HV. The role of magnetic resonance imaging in elucidating the pathogenesis of cerebral palsy: a systematic review. Dev Med Child Neurol J. 2007;49 (4):2.

37. Karen L. Kwong YCW, Chek M. Fong, Sik N. Wong, Kwan T. So. Magnetic resonance imaging in 122 children with spastic cerebral palsy. Pediatric Neurology. 2004;31 (3):4.

38. Gururaj A, Sztriha L, Dawodu A, Nath KR, Varady E, Nork M, et al. CT and MR patterns of hypoxic ischemic brain damage following perinatal asphyxia. Journal of tropical pediatrics. 2002;48 (2):5-9.

39. Towsley K, Shevell MI, Dagenais L, Consortium R. Population-based study of neuroimaging findings in children with cerebral palsy. European journal of paediatric neurology: EJPN: official journal of the European Paediatric Neurology Society. 2011;15 (1):29-35

40. Himmelmann K, Hagberg G, Beckung E, Hagberg B, Uvebrant P. The changing panorama of cerebral palsy in Sweden. IX. Prevalence and origin in the birth-year period 1995-1998. Acta paediatrica. 2005;94 (5):28794.

41. Himmelmann K, Hagberg G, Uvebrant P. The changing panorama of cerebral palsy in Sweden. X. Prevalence and origin in the birth-year period 1999-2002. Acta paediatrica. 2010;99 (1):1337-43.

\section{Source of Support: Nil; Conflict of Interest: None}

Submitted: 22-11-2018; Accepted: 20-12-2018; Published online: 29-12-2018 